\title{
Spectroscopic and crystallographic characterization of two cathinone derivatives: 1-(4-fluorophenyl)-2-(methylamino)pentan-1-one (4-FPD) hydrochloride and 1-(4-methylphenyl)-2-(ethylamino)pentan-1-one (4-MEAP) hydrochloride
}

\author{
Marcin Rojkiewicz · Piotr Kuś ${ }^{1}$ Joachim Kusz ${ }^{2}$ Maria Książek ${ }^{2}$
}

Received: 14 September 2017 / Accepted: 3 November 2017 / Published online: 17 November 2017

(c) The Author(s) 2017. This article is an open access publication

\begin{abstract}
Purpose In this study, we performed identification and physicochemical characterization of two cathinone derivatives, 4-FPD and 4-MEAP, found in market-available materials.

Methods The compounds were characterized by electrospray ionization ion trap mass spectrometry (MS) in $\mathrm{MS}^{2}$ and $\mathrm{MS}^{3}$ modes, gas chromatography-MS, infrared, Raman and ultraviolet-visible spectroscopies, X-ray crystallography, differential scanning calorimetry and nuclear magnetic resonance spectroscopy.

Results We could obtain detailed and comprehensive physicochemical characterization of 4-FPD and 4-MEAP—new cathinone derivatives available on the designer drugs market.

Conclusions Dynamic growth in the number of psychoactive substances available on the designer drug markets makes it compulsory to obtain analytical data allowing unequivocal identification of these drugs in the fastest possible way. In this study we presented analytical data useful in quick identification of the investigated compounds.
\end{abstract}

Keywords 4-FPD · 4-MEAP · Mass spectrometry $\cdot$ X-ray crystallography $\cdot$ Infrared and Raman spectroscopies $\cdot$ NMR spectroscopy

\section{Introduction}

New psychoactive substances (NPS) have been progressively replacing classical narcotics on the illegal drug market. Among most prominent compounds of this type are synthetic cathinones and synthetic cannabinoids. Because of widespread abuse of such designer drugs ("legal highs"), the associated health risks and high frequency of novel

Electronic supplementary material The online version of this article (https://doi.org/10.1007/s11419-017-0393-6) contains supplementary material, which is available to authorized users.

Marcin Rojkiewicz

marcin.rojkiewicz@us.edu.pl

1 Department of Organic Synthesis, Institute of Chemistry, University of Silesia, 9 Szkolna Street, 40-006 Katowice, Poland

2 Department of Crystal Physics, Institute of Physics, University of Silesia, 4 Uniwersytecka Street, 40-007 Katowice, Poland drug variants constantly emerging on the market, numerous studies of these psychoactive substances were undertaken in recent years [1-7].

Synthetic cathinones are a broad group of "designer drugs". Biological effects of their action are similar to those caused by amphetamine or cocaine $[8,9]$. They are marketed either as collectibles ("not suitable for human consumption") or as "research chemicals". Synthetic cathinones are akin to amphetamines, and the only difference between synthetic cathinones and the respective amphetamines is the presence of a carbonyl group in the $\beta$-position with respect to the amino group in cathinone derivatives. For this reason, synthetic cathinones are called bk-amphetamines. Since cathinone is a $\beta$-keto derivative of amphetamine, it stimulates and shows sympathomimetic action upon the central nervous system. The action of cathinone and its derivatives relies mainly on inhibiting reuptake of neurotransmitters; this results in their increased concentration in the inter-synaptic space and stronger activation of cathinone-sensitive receptors. Additionally, relatively strong inhibitory actions of 
cathinone derivatives towards monoamine oxidase (MAO) and higher selectivity of the cathinone derivatives toward MAO-B isoenzyme have been reported [10]. Inhibition of the isoenzyme, normally metabolizing dopamine, prevents degradation of the important neurotransmitter. It can be assumed that synthetic cathinones show affinity towards monoamine transporters responsible for endogenous amines, such as serotonin or dopamine, by increasing their concentration in inter-synaptic space $[11,12]$. Health effects of various market-available synthetic cathinones can differ. Peripheral nervous system effects of cathinone derivative abusers include dilated pupils, elevated blood pressure or hyperthermia. Psychoactive effects of these compounds include states of increased excitement, elevated assertiveness, euphoria, better concentration, anxiety, restlessness or hallucinations. Withdrawal symptoms include sleeplessness, irritability, concentration problems, depression and various psychoses. Long-term abuse of cathinone derivatives may be destructive for both nervous as well as blood vascular systems and may result in irreversible mental disorders. The literature reports and subjective accounts of cathinone derivative abusers have cited occurrence of panic attacks, convulsions, hallucinations, aggressive behavior, chest pain, hypothermia and many other symptoms, which are sometimes life-threatening [1, 13-18].

In this study, we performed identification and physicochemical characterization of two cathinone derivatives, 4-FPD and 4-MEAP (Fig. 1), found as market-available materials. To characterize both substances, data were obtained by electrospray ionization/ion trap mass spectrometry (MS) in $\mathrm{MS}^{2}$ and $\mathrm{MS}^{3}$ modes, gas chromatography-mass spectrometry (GC-MS), infrared (IR), Raman and ultraviolet-visible (UV-VIS) spectroscopies, X-ray crystallography, differential scanning calorimetry (DSC) and nuclear magnetic resonance (NMR) spectroscopy. To our knowledge, this is the first comprehensive report detailing identification and characterization of 4-FPD and 4-MEAP, two cathinones available on the NPS market, though some selected data for 4-MEAP have been available previously [19, 20].

\section{Materials and methods}

\section{Chemicals}

All reagents used were of the HPLC and MS grade. Water (Chromasolv), methanol, deuterated dimethyl sulfoxide (DMSO- $d_{6}$ for NMR analysis) were purchased from SigmaAldrich (Poznań, Poland).

\section{Sample preparation}

The analyzed samples were purchased in Poland in mid2017 from an Internet vendor. Both samples were delivered in powdered forms, which were found pure without any additive by some spectroscopies and chromatographies. The samples were sold as "4-FPD" (compound 1) and "4-methyl pentedrone" (compound 2) and were thus analyzed without any purification. For gas chromatography studies, a $10-\mathrm{mg}$ aliquot of each sample was dissolved in $1 \mathrm{~mL}$ methanol by ultrasonication (10 min). Each $10 \mu \mathrm{L}$ aliquot of such solution was collected and diluted 100-fold with methanol and analyzed. For NMR spectroscopic analysis, $10 \mathrm{mg}$ of the powder sample was dissolved in $0.6 \mathrm{~mL}$ DMSO- $d_{6}$. For DSC, IR, Raman and UV-VIS studies, $5 \mathrm{mg}$ of each sample was taken. The DSC, IR and Raman analyses were performed without any further sample treatment, and for the UV-VIS analysis the samples were dissolved in methanol, diluted tenfold with methanol before analysis.

\section{GC-MS analysis}

For GC-MS analysis, the Thermo Trace Ultra chromatograph was used, coupled with the Thermo DSQ mass spectrometer (Thermo Scientific, Warsaw, Poland). The analyses were carried out using the Rxi ${ }^{\circledR}-5$ Sil MS column ( $30 \mathrm{~m} \times 0.25 \mathrm{~mm}$ i.d., $0.25 \mu \mathrm{m}$ film thickness; Restek, Bellefonte, PA, USA). The following working parameters were employed: injector temperature, $260{ }^{\circ} \mathrm{C}$; oven temperatures, $100{ }^{\circ} \mathrm{C}$ for $2 \mathrm{~min}$, ramp at $20{ }^{\circ} \mathrm{C} / \mathrm{min}$ to $260{ }^{\circ} \mathrm{C}$; carrier gas (helium) flow rate, $1.2 \mathrm{~mL} \mathrm{~min}^{-1}$; MS transfer line temperature, $250{ }^{\circ} \mathrm{C}$; MS source temperature, $250^{\circ} \mathrm{C}$; injection
Fig. 1 Structures of 1-(4-fluorophenyl)-2(methylamino)pentan1-one (4-FPD) (a) and 1-(4-methylphenyl)-2(ethylamino)pentan-1-one (4-MEAP) (b)
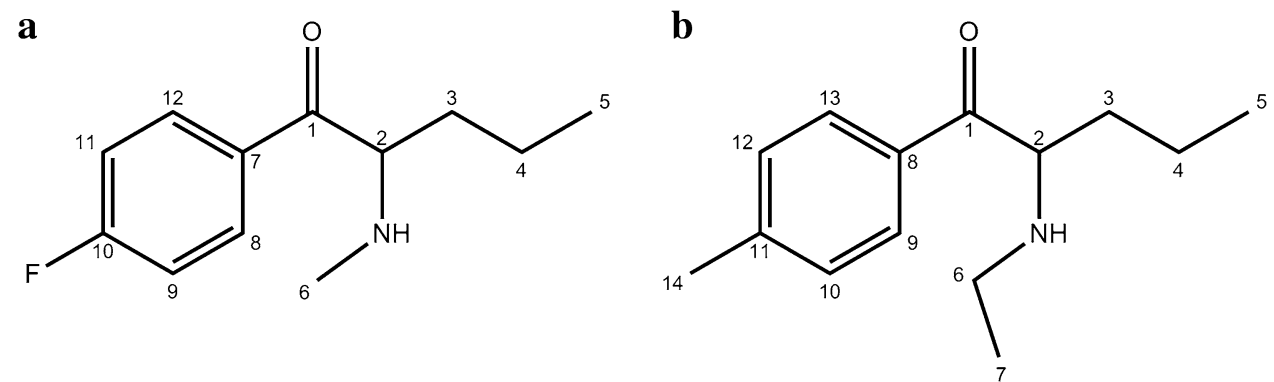
volume, $1 \mu \mathrm{L}$ in the splitless mode. For structural confirmation, electron ionization (EI) mass spectra were matched to an EI-MS library [21].

\section{Electrospray ionization-mass spectrometry ${ }^{n}$}

A Varian MS-500 mass spectrometer with electrospray ionization source (Varian Inc., Palo Alto, CA, USA) was used. The obtained data were processed using MS Workstation software (Varian Inc.). The analytes were electrosprayed in the positive mode (ESI(+)-MS). Fragmentation in the ESI$\mathrm{MS}^{2}$ and ESI-MS ${ }^{3}$ mode was carried out in the scanning range of $\mathrm{m} / \mathrm{z} 50-500$. The source temperature was $350^{\circ} \mathrm{C}$, and the carrier and ionizing gases were nitrogen and helium, respectively.

\section{NMR spectroscopy}

The NMR spectra were recorded using UltraShield $400 \mathrm{MHz}$ apparatus (Bruker, Bremen, Germany) with DMSO- $d_{6}$ as solvent. The data were collected with the chemical shifts referenced to a residual solvent signal.

\section{Fourier transform infrared, Raman and UV-VIS spectroscopies}

Each IR spectrum (wavenumber range $3500-400 \mathrm{~cm}^{-1}$ ) of each evidence material was acquired using a Nicolet iS50 FT-IR spectrometer (Thermo Scientific) and the attenuated total reflectance technique. Raman measurements were performed using a Thermo Scientific ${ }^{\mathrm{TM}} \mathrm{DXR}^{\mathrm{TM}} 2 \mathrm{xi}$ Raman imaging microscope equipped with a $780 \mathrm{~nm}$ laser (Thermo Scientific). UV-VIS absorption spectra of methanol-dissolved samples were recorded using the PerkinElmer Lambda Bio 40 UV-Vis spectrometer $(\lambda=200-1000 \mathrm{~nm})$ (PerkinElmer, Kraków, Poland).

$\mathbf{a}$

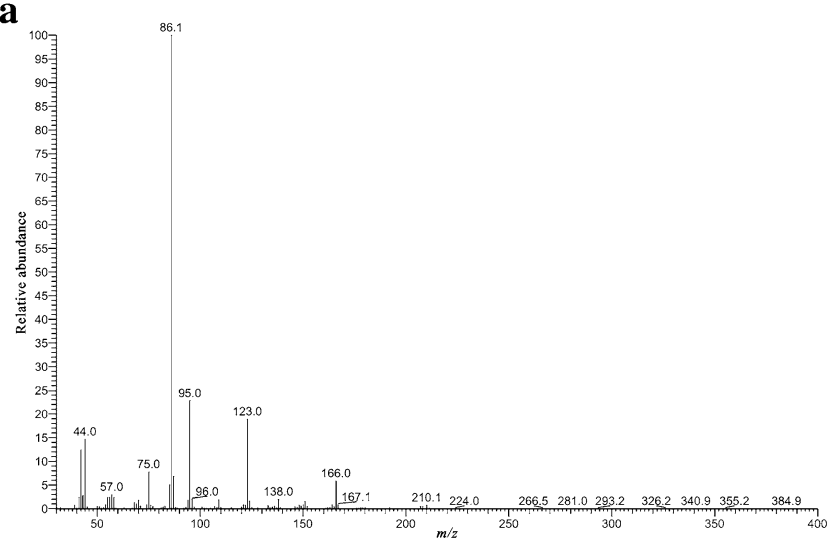

\section{Differential scanning calorimetry}

DSC was performed with a TA-DSC 2010 apparatus (TA Instruments, New Castle, DE, USA) under nitrogen using aluminum sample pans in a temperature range from $20^{\circ} \mathrm{C}$ to over the clearing point.

\section{X-ray spectroscopy}

The single crystal X-ray experiments for both compounds were performed at $100 \mathrm{~K}$. The data were collected using a SuperNova kappa diffractometer with Atlas CCD detector (Agilent Technologies, Santa Clara, CA, USA). For the integration of the collected data, the CrysAlis ${ }^{\text {Pro }}$ software (version 1.171.38.41q, 2015; Rigaku Oxford Diffraction, Sevenoaks, UK) was used. The solving and refining procedures were similar for both compounds. The structures were solved using direct methods with the SHELXS97 software, and the solutions were refined using SHELXL-2014/7 program [22]. CCDC 1573894-1573895 contains supplementary crystallographic data for this paper. These data can be obtained free of charge from The Cambridge Crystallographic Data Centre via: http://www.ccdc.cam.ac.uk/data_request/cif.

\section{Results and discussion}

\section{GC-MS and ESI-MS ${ }^{n}$}

The samples were analyzed by GC-MS, and the resulting mass spectra of compounds $\mathbf{1}$ and $\mathbf{2}$ are shown in Fig. 2. The spectra were subjected to examination whether they hit specific compounds in the EI-MS library; as results compounds 1 and 2 were found to be possibly 4-FPD and 4-MEAP, respectively.

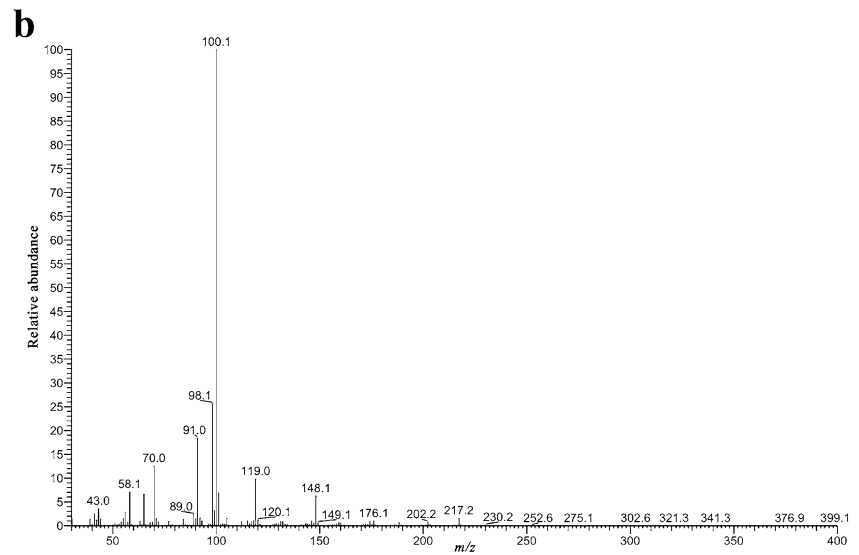

Fig. 2 Gas chromatography-electron ionization-mass spectrometry (GC-EI-MS) spectra of compounds 1 (a) and 2 (b) 
In the mass spectra obtained in the EI-MS mode, each main fragment ion was detected for compounds $\mathbf{1}$ and $\mathbf{2}$ at $\mathrm{m} / \mathrm{z} 86$ and 100, respectively. Other less intense fragments present in the spectra were at $\mathrm{m} / \mathrm{z} 95$ and 123 for 4-FPD (1) and at $m / z 91$ and 119 for 4-MEAP (2). Possible structures of the fragmentation products derived from the parent structures of compounds $\mathbf{1}$ and $\mathbf{2}$ are presented in Fig. 3, and were in accordance with reported fragmentation pathways of other cathinone derivatives [23]. The obtained spectra were almost identical with those originating from 4-FPD and 4-MEAP standards [20, 21]. Also, comparison of our data with those for a well-known stimulant pentedrone has revealed the presence of the same base peak $(\mathrm{m} / \mathrm{z}, 86)$ in the case of compound $\mathbf{1}$, which suggests bond cleavage between carbon atoms 1 and 2 (carbon numbering shown in Fig. 1). The difference of 14 Da between $\mathrm{m} / \mathrm{z}$ 86 (4-FPD and pentedrone) and $m / z 100$ (4-MEAP) corresponds well with the presence of an additional methyl group in compound 2. Furthermore, other differences in $\mathrm{m} / \mathrm{z}$ values seen in the mass spectra of compounds $\mathbf{1}$ and 2 result from the presence of different moieties, as compared to pentedrone, confirming validity of the proposed fragmentation pathways.

In the ESI-MS spectrum, the protonated molecule $[\mathrm{M}+\mathrm{H}]^{+}$was seen at $\mathrm{m} / \mathrm{z} 210$ for compound 1 (4-FPD) and at $m / z 220$ for compound 2 (4-MEAP). The samples were also analyzed by tandem and triple stage mass spectrometry $\left(\mathrm{MS}^{2}\right.$ and $\mathrm{MS}^{3}$ ), using direct infusion. In the $\mathrm{MS}^{2}$ mode, elimination of a water molecule for both compounds was observed $\left[\mathrm{M}+\mathrm{H}-\mathrm{H}_{2} \mathrm{O}\right]^{+}$, which is characteristic for cathinone derivatives [24]. The probable fragmentation pathways in the $\mathrm{MS}^{2}$ and $\mathrm{MS}^{3}$ modes for $\mathbf{1}$ and $\mathbf{2}$ are presented in Fig. 4. The above analyses of the spectra by both EI-MS and ESI-MS ${ }^{n}$ further support the idea that compounds 1 and 2 are 4-FPD and 4-MEAP, respectively.

\section{${ }^{1} \mathrm{H}$ and ${ }^{13} \mathrm{C}$ NMR spectroscopy}

NMR spectroscopy was employed to confirm the structures of investigated compounds. The data for compounds $\mathbf{1}$ and $\mathbf{2}$ are presented in Tables 1 and 2, respectively (atom numbering according to Fig. 1).

Because of interaction of protons with fluorine in the 4-FPD molecule, instead of a classical set of signals in ${ }^{1} \mathrm{H}$ NMR spectrum in the aromatic region (i.e., dd), a number of multiplets were observed for each group of equivalent protons. Also in the ${ }^{13} \mathrm{C}$ NMR spectrum, the coupling of carbon with the fluorine atom could be observed that explains splitting in the carbon signals (Table 1 ). The ${ }^{1} \mathrm{H}$ and ${ }^{13} \mathrm{C}$ NMR spectra for compounds $\mathbf{1}$ and $\mathbf{2}$ are available in the electronic supplementary material (Figs. S1-S4). The NMR data confirmed the identification of compounds $\mathbf{1}$ and $\mathbf{2}$ to be 4-FPD and 4-MEAP, respectively.

\section{IR, Raman and UV-VIS spectra}

IR and Raman techniques can be useful in characterizing designer cathinones, especially identifying characteristic functional groups. In the IR spectra, a strong carbonyl stretch at $1688 \mathrm{~cm}^{-1}$ was observed for both compounds. Also, the aliphatic and aromatic $\mathrm{C}-\mathrm{H}$ stretching at $2700-3000 \mathrm{~cm}^{-1}$ and the amine hydrochloride salt
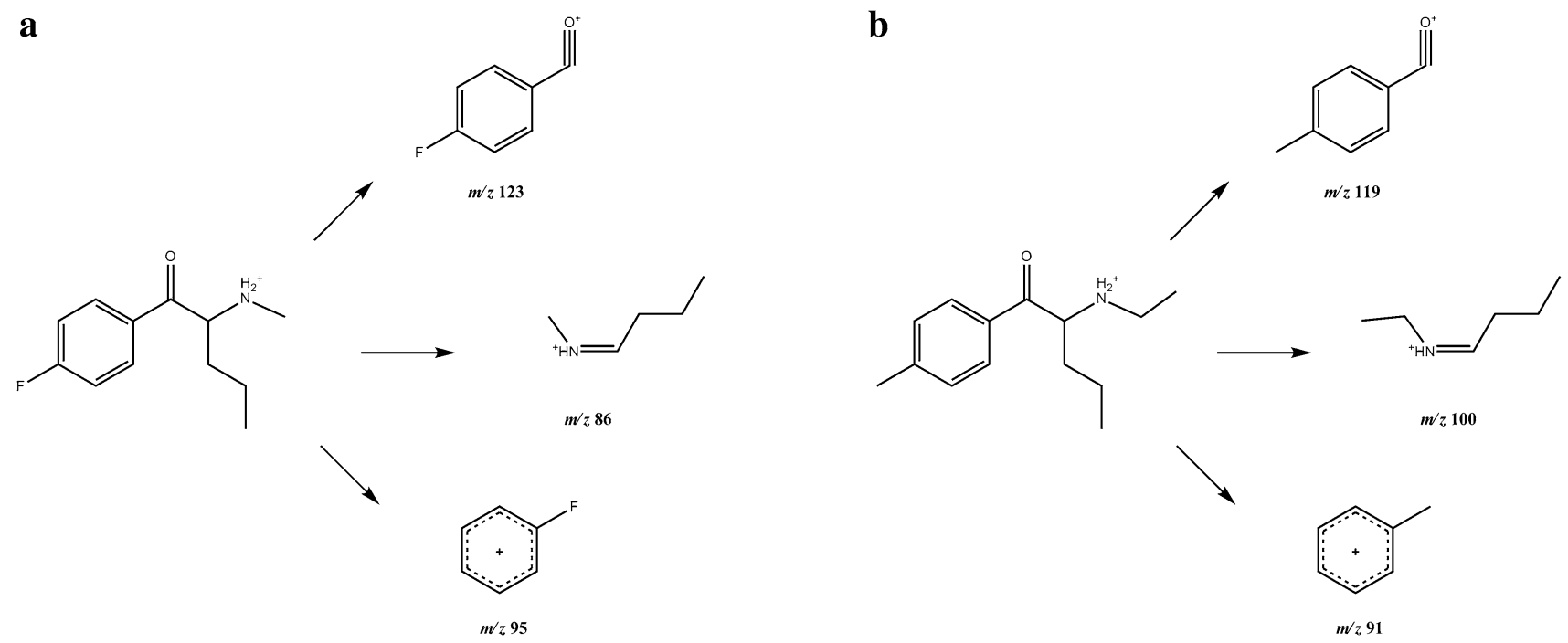

Fig. 3 GC-EI-MS fragmentation pathways of compounds 1 (a) and 2 (b) 
a<smiles>C=N/C=C\c1ccc(F)cc1</smiles>

b<smiles>CCCC([NH2+]CC)C(=O)c1ccc(C)cc1</smiles>

$m / z 220$<smiles>CC=[NH+]C(=Cc1ccc(C)cc1)CCC</smiles>

$m / z 202$

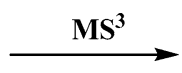

$\mathbf{M S}^{3}$<smiles>CCCCC(=O)c1ccc(C)cc1</smiles>

$m / z 175$<smiles>C/C=[NH+]\C=C/c1ccc(C)cc1</smiles>

$m / z 160$<smiles>Cc1ccc(C)cc1</smiles>

$m / z 105$

Fig. 4 Electrospray ionization-MS (ESI-MS) fragmentation pathways of compounds 1 (a) and 2 (b) in $\mathrm{MS}^{2}$ and $\mathrm{MS}^{3}$ modes

Table $1{ }^{1} \mathrm{H}$ and ${ }^{13} \mathrm{C}$ nuclear magnetic resonance (NMR) data for compound 1 (4-FPD)

\begin{tabular}{lll}
\hline Atom position & Carbon chemical shifts $(\mathrm{ppm})$ & Proton chemical shifts $(\mathrm{ppm})$ \\
\hline 1 & 195.31 & - \\
2 & 62.31 & $5.26(\mathrm{t}, J=5.3 \mathrm{~Hz}, 1 \mathrm{H})$ \\
3 & 31.98 & $1.78-1.87(\mathrm{~m}, 1 \mathrm{H}) ; 1.90-1.98(\mathrm{~m}, 1 \mathrm{H})$ \\
4 & 31.78 & $1.02-1.15(\mathrm{~m}, 1 \mathrm{H}) ; 1.26-1.38(\mathrm{~m}, 1 \mathrm{H})$ \\
5 & 14.10 & $0.78(\mathrm{t}, J=7.3 \mathrm{~Hz}, 3 \mathrm{H})$ \\
6 & 17.54 & $2.56(\mathrm{~s}, 3 \mathrm{H})$ \\
7 & 131.30 & - \\
8,12 & $132.37 ; 132.47\left(J_{\mathrm{C}-\mathrm{C}-\mathrm{C}-\mathrm{F}}=9.8 \mathrm{~Hz}\right)$ & $8.17(\mathrm{~m}, 2 \mathrm{H})$ \\
9,11 & $116.51 ; 116.53\left(J_{\mathrm{C}-\mathrm{C}-\mathrm{F}}=22.1 \mathrm{~Hz}\right)$ & $7.45(\mathrm{~m}, 2 \mathrm{H})$ \\
10 & $165.02 ; 167.55\left(J_{\mathrm{C}-\mathrm{F}}=254.4 \mathrm{~Hz}\right)$ & - \\
$\mathrm{N}-\mathrm{H}$ & - & $9.59(\mathrm{bs}, 2 \mathrm{H})$ \\
\hline
\end{tabular}

The numbering of carbon atoms is given in Fig. 1 
Table $2{ }^{1} \mathrm{H}$ and ${ }^{13} \mathrm{C}$ NMR data for compound 2 (4-MEAP)

\begin{tabular}{lll}
\hline Atom position & $\begin{array}{l}\text { Carbon chemi- } \\
\text { cal shifts }(\mathrm{ppm})\end{array}$ & Proton chemical shifts $(\mathrm{ppm})$ \\
\hline 1 & 196.26 & - \\
2 & 60.72 & $5.23(\mathrm{t}, J=5.2 \mathrm{~Hz}, 1 \mathrm{H})$ \\
3 & 32.36 & $1.82-1.98(\mathrm{~m}, 2 \mathrm{H})$ \\
4 & 17.70 & $1.01-1.34(\mathrm{~m}, 1 \mathrm{H}) ; 1.22-1.37$ \\
& & $(\mathrm{~m}, 1 \mathrm{H})$ \\
5 & 11.56 & $0.77(\mathrm{t}, J=7.3 \mathrm{~Hz}, 3 \mathrm{H})$ \\
6 & 41.59 & $2.84-2.92(\mathrm{~m}, 1 \mathrm{H}) ; 2.97-3.06$ \\
& & $1.27(\mathrm{t}, J=7.2 \mathrm{~Hz}, 3 \mathrm{H})$ \\
7 & 14.14 & - \\
8 & 132.17 & $7.99(\mathrm{~d}, J=8.2 \mathrm{~Hz}, 2 \mathrm{H})$ \\
9,13 & 129.33 & $7.41(\mathrm{~d}, J=8.0 \mathrm{~Hz}, 2 \mathrm{H})$ \\
10,12 & 130.18 & - \\
11 & 145.93 & $2.87(\mathrm{~s}, 3 \mathrm{H})$ \\
14 & 21.73 & $9.14(\mathrm{bs}) ; 9.74(\mathrm{bs})$ \\
$\mathrm{N}-\mathrm{H}$ & - &
\end{tabular}

The numbering of carbon atoms is given in Fig. 1 bands can be observed for both compounds. Characteristic $\mathrm{C}-\mathrm{C}$ vibrations in an aromatic ring appeared at 1598 and $1605 \mathrm{~cm}^{-1}$ for 4-FPD (1) and 4-MEAP (2), respectively. In the Raman spectroscopy, strong $\mathrm{C}=\mathrm{O}$ bands were observed at $1690 \mathrm{~cm}^{-1}$ for both compounds. The $\mathrm{C}-\mathrm{C}$ aromatic bands in the Raman spectra gave actually the same wavenumber values as in the IR spectra. Both IR and Raman spectra were very similar for compounds $\mathbf{1}$ and $\mathbf{2}$. This is probably due to structural similarity of the investigated compounds. The IR and Raman spectra for compounds $\mathbf{1}$ and $\mathbf{2}$ are available in the electronic supplementary material (Figs. S5-S8). The UV spectra recorded by UVVIS spectrometry showed absorption maxima at 253 and $265 \mathrm{~nm}$ for the compounds $\mathbf{1}$ and $\mathbf{2}$, respectively.

\section{Melting points}

Melting points for compounds 1 (4-FPD hydrochloride) and 2 (4-MEAP hydrochloride) obtained by DSC analysis were 245 and $223{ }^{\circ} \mathrm{C}$, respectively; those measured in the classical
Table 3 Crystal data and structure refinements for compounds 1 (4-FPD) and 2 (4-MEAP)

\begin{tabular}{|c|c|c|}
\hline & Compound 1 & Compound 2 \\
\hline Molecular formula & $\mathrm{C}_{12} \mathrm{H}_{17} \mathrm{FNOCl}$ & $\mathrm{C}_{14} \mathrm{H}_{22} \mathrm{NOCl}$ \\
\hline Molecular weight & 245.71 & 255.78 \\
\hline Crystal system & Monoclinic & Monoclinic \\
\hline Space group & $P 2_{l} / c$ & $P 2_{1} / n$ \\
\hline Temperature $(K)$ & 100 & 100 \\
\hline$a(\AA)$ & $11.9884(2)$ & $7.1344(2)$ \\
\hline$b(\AA)$ & $9.6621(2)$ & $24.7843(6)$ \\
\hline$c(\AA)$ & $10.6669(2)$ & $8.0352(2)$ \\
\hline$\alpha\left({ }^{\circ}\right)$ & 90 & 90 \\
\hline$\beta\left(\left(^{\circ}\right)\right.$ & $90.944(2)$ & $91.170(2)$ \\
\hline$\gamma\left({ }^{\circ}\right)$ & 90 & 90 \\
\hline$V\left(\AA^{3}\right)$ & $1235.41(4)$ & $1420.50(6)$ \\
\hline $\mathrm{Z}$ & 4 & 4 \\
\hline $\mathrm{Dx}\left(\mathrm{g} \mathrm{cm}^{-3}\right)$ & 1.321 & 1.196 \\
\hline Absorption coeff. $\left(\mathrm{mm}^{-1}\right)$ & 0.301 & 0.255 \\
\hline$F(000)$ & 520 & 552 \\
\hline Crystal size (mm) & $0.12 \times 0.07 \times 0.03$ & $0.10 \times 0.07 \times 0.03$ \\
\hline \multicolumn{3}{|l|}{ Data collection and structure solution } \\
\hline Data collected & 10,651 & 21,277 \\
\hline Independent reflections & 2524 & 2894 \\
\hline Observed reflections $[I>2 \sigma(I)]$ & 2353 & 2766 \\
\hline$R$ (int.) & 0.018 & 0.030 \\
\hline Completeness (\%) & 99.9 & 99.9 \\
\hline$T_{\max } / T_{\min }$ & $1.000 / 0.900$ & $1.000 / 0.779$ \\
\hline No. of parameters & 147 & 158 \\
\hline $\mathrm{R} 1[I>2 \sigma(I)]$ & 0.025 & 0.035 \\
\hline$w R 2$ (all data) & 0.069 & 0.083 \\
\hline S & 1.055 & 1.093 \\
\hline Largest difference peak and hole $\left(e \AA^{-3}\right)$ & $0.33,-0.21$ & $0.25,-0.19$ \\
\hline
\end{tabular}


$\mathbf{a}$

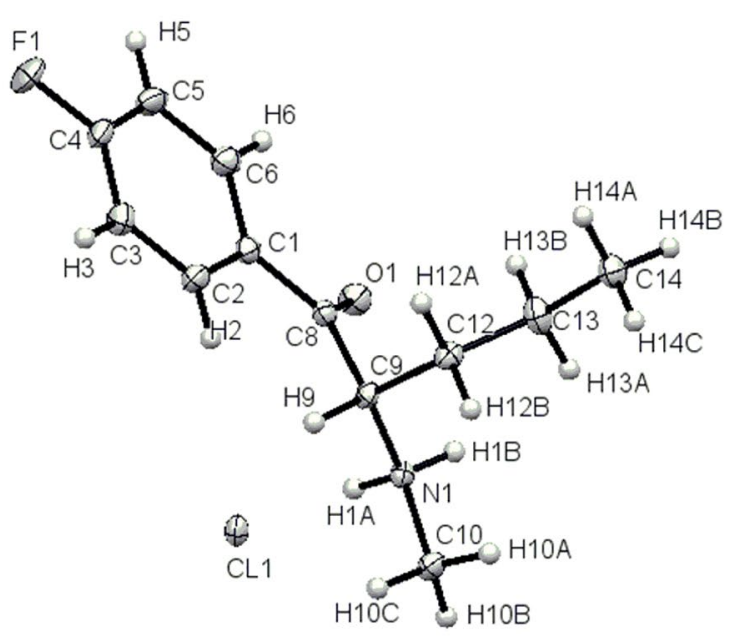

b

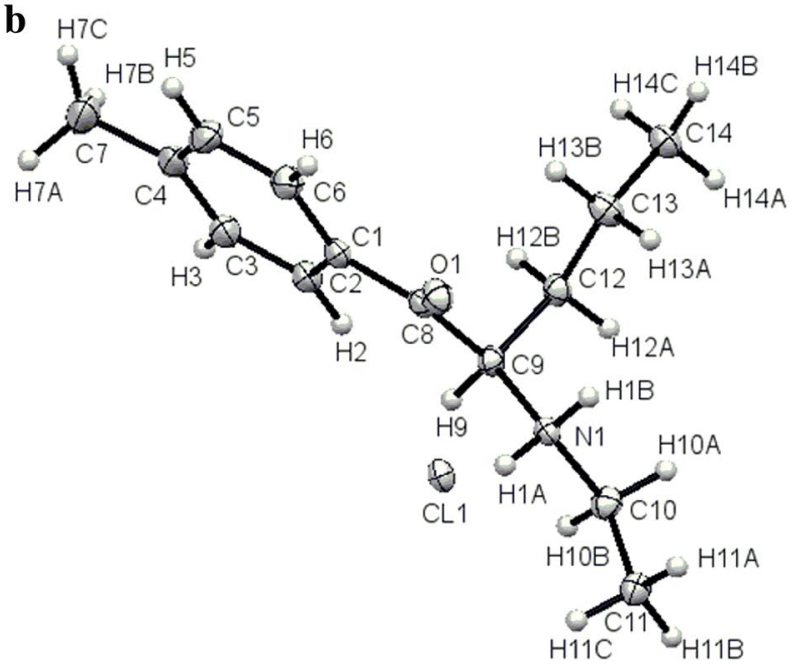

Fig. 5 Molecular structures of compounds 1 (4-FPD hydrochloride) (a) and 2 (4-MEAP hydrochloride) (b), showing atom-labeling schemes. Ellipsoids representing displacement parameters are drawn at the $50 \%$ probability level

way were $243-245{ }^{\circ} \mathrm{C}$ and $220-222{ }^{\circ} \mathrm{C}$, respectively. Both compounds melted with decomposition.

\section{X-ray studies}

Crystal data and structure refinements for both compounds are summarized in Table 3. The molecular structures of compounds 1 (4-FPD hydrochloride) and 2 (4-MEAP hydrochloride) are shown in Fig. 5. Packing diagrams for both compounds are shown in Fig. 6. All distances, angles and planarity of ring systems are typical. In the crystals of both compounds, a racemic mixture was present. Compounds $\mathbf{1}$ and 2 have two enantiomeric ion pairs in the unit of the crystal lattices.

\section{Compound 1}

Two aromatic rings are laid above each other (Fig. 7) with centroid distance equal to $3.734 \AA$ ( $109.22^{\circ}$ angle), in parallel planes separated by $3.473 \AA$. The shortest distance between oxygen and carbon atoms in the $N$-methyl group of the adjacent molecule was $3.185 \AA$. The structure featured many other weak hydrogen interactions, for exam-

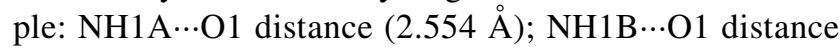
$(2.629 \AA)$ and $\mathrm{C} 13 \mathrm{H} \cdots \mathrm{O} 1$ distance $(2.719 \AA)$, all of them shorter than the sum of the van der Waals radii. The shortest distance between the hydrogen atom of the methane group and $\mathrm{Cl}^{-}$ion was $2.606 \AA$, which is smaller than the sum of the van der Waals radii $(2.96 \AA)$. Equally short distances between hydrogen as well as nitrogen atoms and $\mathrm{Cl}^{-}$ions can be found in the structure of this compound (the shortest $\mathrm{NH}^{\cdots} \cdot \mathrm{Cl}^{-}=2.240 \AA$ and $\mathrm{N} \cdots \mathrm{Cl}^{-}=3.060 \AA$ with the sum of van der Waals radii $=2.95$ and $3.30 \AA$, respectively). Other short distances occurring in the structure of compound $\mathbf{1}$ are shown in Fig. S9.

\section{Compound 2}

The structure of compound 2 lacked strong hydrogen bonds. Weak hydrogen bonds occur inside the molecule in the crystal lattice: O1 ‥ H13B distance was $2.825 \AA$; the distances between oxygen atom and two hydrogen atoms in the amine group were: $\mathrm{O} 1 \cdots \mathrm{H} 1 \mathrm{~B}=2.574 \AA$ and $\mathrm{O} 1 \cdots \mathrm{H} 1 \mathrm{~A}=2.576 \AA$, respectively. Of note, molecules of this compound can form pairs in which the $\mathrm{CH} \cdots \pi$, bond may occur, which is shown in Fig. 8. Lengths of these bonds were: center of aromatic ring-hydrogen in the aromatic methyl group $=2.935 \AA$ $\left(131.91^{\circ}\right.$ angle). Aromatic rings lay in parallel planes separated by a distance of $3.460 \AA$. Several $\mathrm{C}-\mathrm{H} \cdots \mathrm{Cl}$ and $\mathrm{N}-\mathrm{H} \cdots \mathrm{Cl}$ short distances testifying to the presence of interactions between molecules or their fragments are shown in Fig. S10.

\section{Conclusions}

Dynamic growth in the number of psychoactive substances available on the designer drug markets makes it compulsory 
Fig. 6 Packing diagram of compounds 1 (4-FPD hydrochloride) (a) and 2 (4-MEAP hydrochloride) (b)

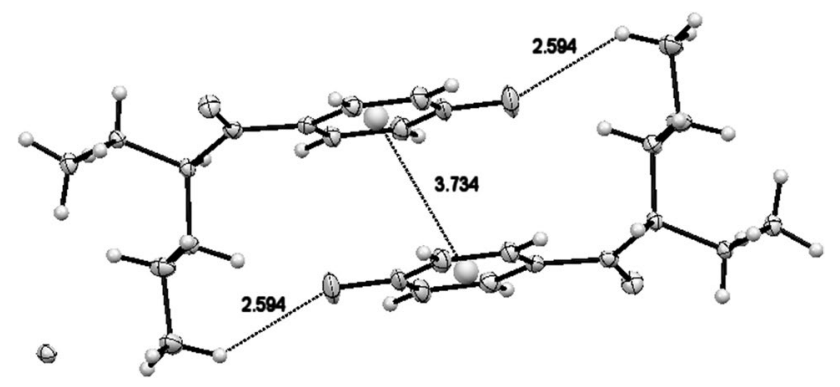

Fig. $7 \mathrm{C}-\mathrm{H} \cdots \mathrm{F}$ and $\pi \cdots \pi$ hydrogen bond motifs in crystal packing of compound 1 (4-FPD hydrochloride) $\mathbf{a}$

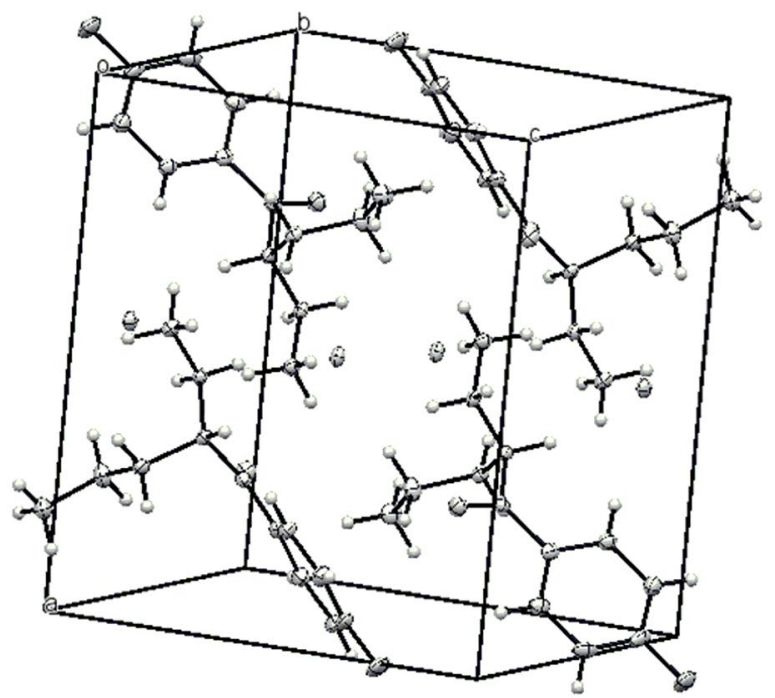

b

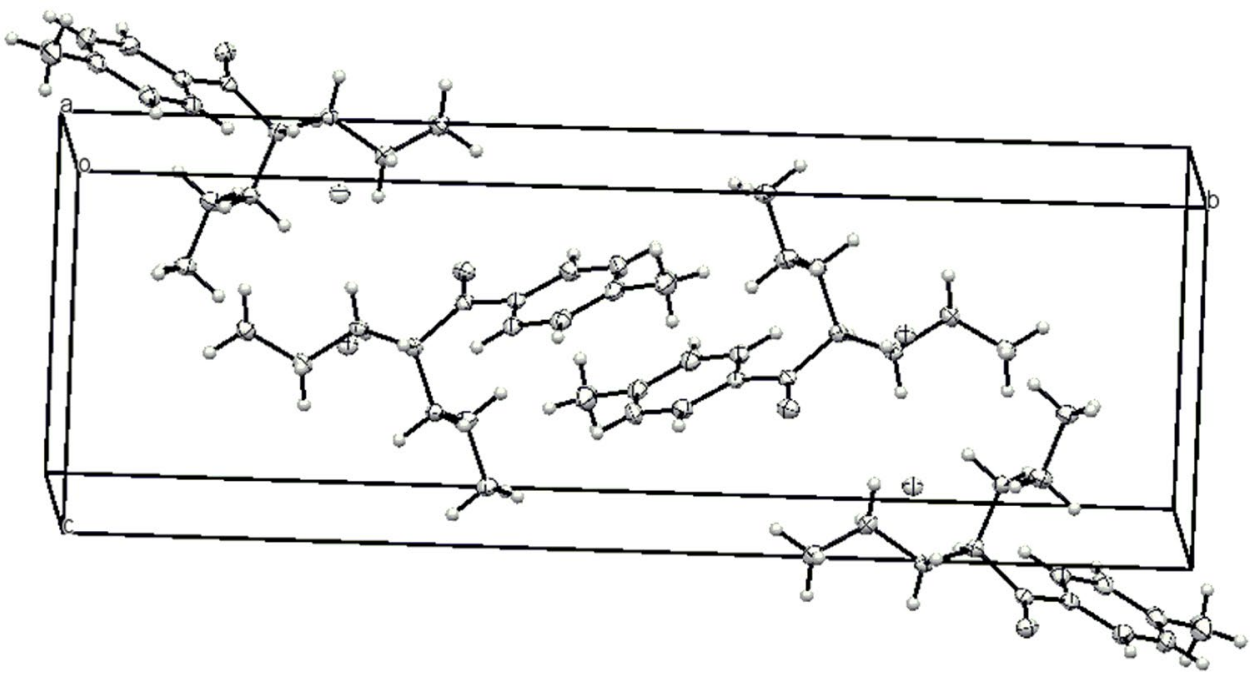

to obtain analytical data allowing unequivocal identification of these drugs in the fastest possible way. This is of paramount importance for both law enforcement agencies and for forensic toxicologists. In the present paper we report physicochemical characteristics of two cathinone derivatives (4-FPD and 4-MEAP). Both compounds were characterized using an ESI/ion trap MS in $\mathrm{MS}^{2}$ and $\mathrm{MS}^{3}$ modes, GC-MS, IR, Raman and UV-VIS spectroscopies, DSC, NMR spectroscopy and X-ray crystallography. Our report is linked to the CCDC repository entry of the compound, where its characteristic data can be found, including elementary cell data particularly useful in quick analysis. 


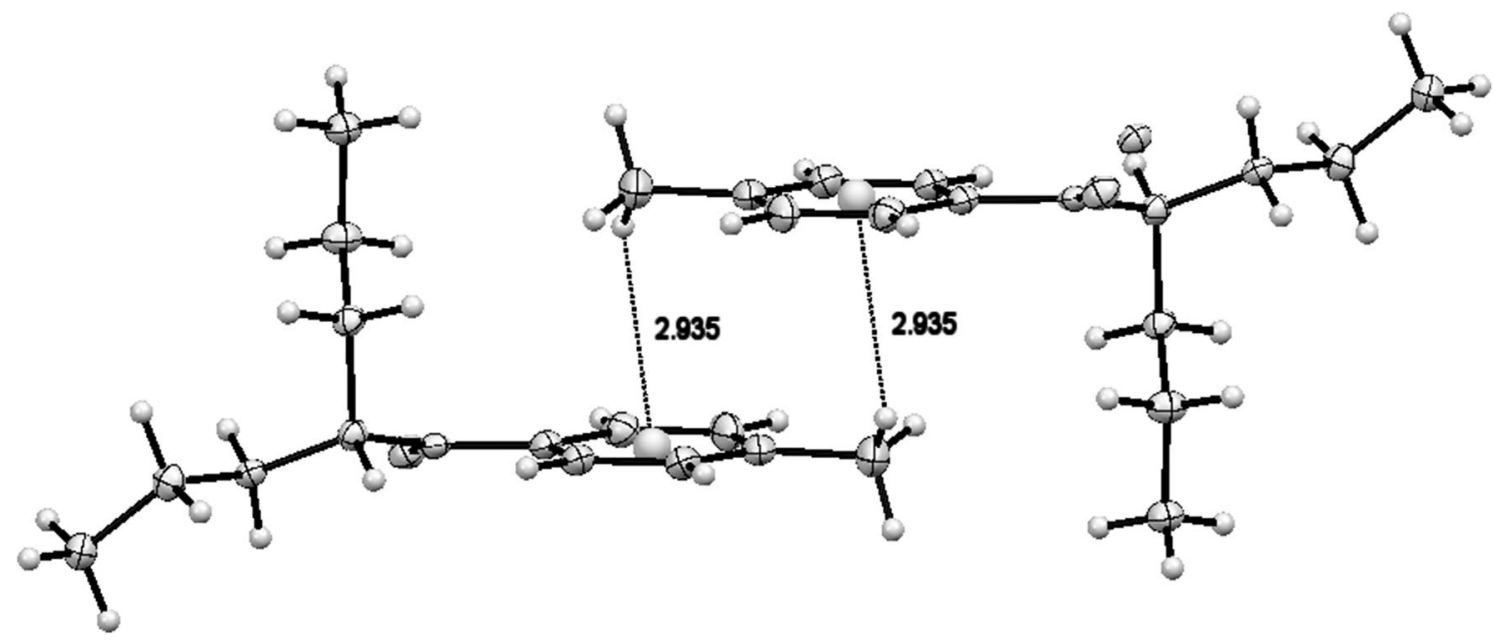

Fig. $8 \mathrm{C}-\mathrm{H} \cdots \pi$ hydrogen bond motifs in crystal packing of compound 2 (4-MEAP hydrochloride)

Although some evidence has been available for 4-MEAP previously (GC-MS, IR and NMR) [19, 20], to our knowledge this study offers the first detailed and comprehensive data for 4-FPD and 4-MEAP.

Acknowledgements We wish to thank Dr. Sławomir Maślanka for DSC measurement and Dr. Barbara Hachuła for IR and Raman spectra measurement.

\section{Compliance with ethical standards}

Conflict of interest The authors declare that they have no conflict of interest.

Ethical approval This article does not contain any studies with human participants or animals performed by any of the authors.

Open Access This article is distributed under the terms of the Creative Commons Attribution 4.0 International License (http://creativecommons.org/licenses/by/4.0/), which permits unrestricted use, distribution, and reproduction in any medium, provided you give appropriate credit to the original author(s) and the source, provide a link to the Creative Commons license, and indicate if changes were made.

\section{References}

1. Zawilska J, Wojcieszak J (2013) Designer cathinones—an emerging class of novel psychoactive substances. Forensic Sci Int 231:42-53

2. Adamowicz P, Geroń J, Gil D, Lechowicz W, Skulska A, Tokarczyk B (2016) The prevalence of new psychoactive substances in biological material-a three-year review of casework in Poland. Drug Test Anal 8:63-70

3. Nycz JE, Malecki G, Zawiazalec M, Pazdziorek T (2011) X-ray structures and computational studies of several cathinones. J Mol Struct 1002:10-18

4. Nycz JE, Pazdziorek T, Malecki G, Szala M (2016) Identification and derivatization of selected cathinones by spectroscopic studies. Forensic Sci Int 266:416-426
5. Zawilska J, Wojcieszak J (2017) $\alpha$-Pyrrolidinophenones: a new wave of designer cathinones. Forensic Toxicol 35:201-216

6. Błażewicz A, Bednarek E, Sitkowski J, Popławska M, Stypułkowska K, Bocian W, Kozerski L (2017) Identification and structural characterization of four novel synthetic cathinones: $\alpha$-methylaminohexanophenone (hexedrone, HEX), 4-bromoethcathinone (4-BEC), 4-chloro- $\alpha$-pyrrolidinopropiophenone (4-ClPPP), and 4-bromo- $\alpha$-pyrrolidinopentiophenone (4-Br-PVP) after their seizures. Forensic Toxicol 35:317-332

7. Kuś P, Kusz J, Książek M, Pieprzyca E, Rojkiewicz M (2017) Spectroscopic characterization and crystal structures of two cathinone derivatives: $N$-ethyl-2-amino-1-phenylpropan-1-one (ethcathinone) hydrochloride and $N$-ethyl-2-amino-1-(4-chlorophenyl)propan-1-one (4-CEC) hydrochloride. Forensic Toxicol 35:114-124

8. Valente MJ, Guedes de Pinho P, de Lourdes Bastos M, Carvalho F, Carvalho M (2014) Khat and synthetic cathinones: a review. Arch Toxicol 88:15-45

9. Prosser JM, Nelson LS (2012) The toxicology of bath salts: a review of synthetic cathinones. J Med Toxicol 8:33-42

10. Osorio-Olivares M, Rezende MC, Sepúlveda-Boza S, Cassels BK, Fierro A (2004) MAO inhibition by arylisopropylamines: the effect of oxygen substituents at the $\beta$-position. Bioorg Med Chem 12:4055-4066

11. Liechti M (2015) Novel psychoactive substances (designer drugs): overview and pharmacology of modulators of monoamine signaling. Swiss Med Wkly 145:w14043. https://doi.org/10.4414/ smw.2015.14043

12. Baumann MH, Solis E, Watterson LR, Marusich JA, Fantegrossi WE, Wiley JL (2014) Bath salts, spice, and related designer drugs: the science behind the headlines. J Neurosci 34:15150-15158

13. Baumann MH, Partilla JS, Lehner KR (2013) Psychoactive "bath salts": not so soothing. Eur J Pharmacol 698:1-5

14. German CL, Fleckenstein AE, Hanson GL (2014) Bath salts and synthetic cathinones: an emerging designer drug phenomenon. Life Sci 97:2-8

15. Lewin AH, Seltzman HH, Carroll FI, Mascarella SW, Reddy PA (2014) Emergence and properties of spice and bath salts: a medicinal chemistry perspective. Life Sci 97:9-19

16. Gregg RA, Rawls SM (2014) Behavioral pharmacology of designer cathinones: a review of the preclinical literature. Life Sci 97:27-30 
17. Glennon RA, Dukat M (2017) Synthetic cathinones: a brief overview of overviews with applications to the forensic sciences. Ann Forensic Res Anal 4(2):1040. https://www.jscimedcentral.com/ Forensic/forensic-4-1040.pdf

18. Romanek K, Stenzel J, Schmoll S, Schrettl V, Geith S, Eyer F, Rabe C (2017) Synthetic cathinones in Southern Germany-characteristics of users, substance-patterns, co-ingestions, and complications. Clin Toxicol 55:573-578

19. Hamby D, Burnett A, Jablonsky M, Twamley B, Kavanagh PV, Gardner EA (2015) Identification of 2-(ethylamino)-1-(4methylphenyl)-1-pentanone (4-MEAP), a new "legal high" sold by an Internet vendor as 4-methyl pentedrone. J Forensic Sci 60:721-726

20. National Forensic Laboratory, Slovenia (2016) Analytical report: 4-MEAP. http://www.policija.si/apps/nfl_response_web/0_Analytical_Reports_final/4-MEAP-ID-1696-16rpt271016.pdf. Accessed August 2017
21. Cayman Chemical (2016) Cayman spectral library. https://www. caymanchem.com/gcms/9002182-0464459-GCMS.pdf. Accessed August 2017

22. Sheldrick GM (2015) Crystal structure refinement with SHELXL. Acta Cryst C 71:3-8

23. Matsuta S, Katagi M, Nishioka H, Kamata H, Sasaki K, Shima N, Kamata T, Miki A, Tatsuno M, Zaitsu K, Tsuboi K, Tsuchihashi H, Suzuki K (2014) Structural characterization of cathinone-type designer drugs by EI mass spectrometry (in Japanese with English abstract). Jpn J Forensic Sci Technol 19:77-89

24. Fornal E (2014) Study of collision-induced dissociation of electrospray-generated protonated cathinones. Drug Test Anal 6:705-715 